\title{
Verification and Validation of Requirements on the CEV Parachute Assembly System Using Design of Experiments
}

\author{
Peter Z. Schulte ${ }^{1}$ and James W. Moore ${ }^{2}$ \\ Jacobs Technology, Engineering \& Science Contract Group (ESCG), Houston, TX, 77598
}

\begin{abstract}
The Crew Exploration Vehicle Parachute Assembly System (CPAS) project conducts computer simulations to verify that flight performance requirements on parachute loads and terminal rate of descent are met. Design of Experiments (DoE) provides a systematic method for variation of simulation input parameters. When implemented and interpreted correctly, a DoE study of parachute simulation tools indicates values and combinations of parameters that may cause requirement limits to be violated. This paper describes one implementation of DoE that is currently being developed by CPAS, explains how DoE results can be interpreted, and presents the results of several preliminary studies. The potential uses of DoE to validate parachute simulation models and verify requirements are also explored.
\end{abstract}

\section{Nomenclature}

$\begin{array}{ll}\text { ANOVA } & =\text { Analysis of Variance } \\ C_{D} & =\text { Drag coefficient } \\ C_{D} S & =\text { Drag area } \\ C_{k} & =\text { Parachute over-inflation factor } \\ \text { CEV } & =\text { Crew Exploration Vehicle } \\ \text { CPAS } & =\text { Crew Exploration Vehicle Parachute Assembly System } \\ \text { DoE } & =\text { Design of Experiments } \\ \text { DSS } & =\text { Decelerator Systems Simulation } \\ \text { DSSA } & =\text { Decelerator Systems Simulation Application } \\ \text { ESCG } & =\text { Engineering and Science Contract Group } \\ \text { expopen } & =\text { Opening profile shape exponent (parachute inflation parameter) } \\ \text { MCDS } & =\text { Monte Carlo Decelerator Simulation } \\ \text { MoE } & =\text { Measure of Effectiveness } \\ n & =\text { Parachute canopy fill constant } \\ \text { NASA } & =\text { National Aeronautics and Space Administration } \\ \bar{q} & =\text { Dynamic pressure } \\ \text { ROD } & =\text { Rate of Descent } \\ t_{k} & =\text { Parachute time to ramp down after stage over-inflation } \\ \varepsilon & =\text { reefing ratio for parachute inflation stage }\end{array}$

\section{Introduction}

$\mathrm{T}$ HE Crew Exploration Vehicle (CEV) Parachute Assembly System (CPAS) is used to recover the Orion vehicle after it reenters the atmosphere from Earth orbit. Because the vehicle will be human-rated, strict requirements are levied on CPAS parachute flight performance by the National Aeronautics and Space Administration (NASA). Parachute loads and terminal rate of descent (ROD) must remain under specified maximum values. ${ }^{1}$ To ensure these requirements are met, the CPAS project conducts computer simulations of parachute performance using NASAdeveloped 6 Degree-of-Freedom modeling tools: the Decelerator System Simulation (DSS) and Decelerator System

\footnotetext{
${ }^{1}$ Co-op Student, Aerothermal and Flight Mechanics, The University of Texas at Austin

${ }^{2}$ CPAS Analysis Engineer, Aerothermal and Flight Mechanics, 455 E. Medical Center Blvd., Webster, TX.
} 
Simulation Application (DSSA). DSS and DSSA utilize input parameters that characterize the behavior of parachutes. These parameters are varied within specified dispersion ranges, and simulation results are analyzed to verify that requirements are met. Design of Experiments (DoE) provides a method to capture the effects of many possible combinations of parameters. In turn, DoE can potentially be used by CPAS to validate simulation models and verify parachute flight performance requirements. ${ }^{2}$

Table 1. Example $3^{3}$ Full Factorial Study Levels: $1=$ minimum value, $2=$ nominal value, $3=$ maximum value

\begin{tabular}{|c|c|c|c|}
\hline Case & Var1 & Var2 & Var3 \\
\hline $\mathbf{1}$ & 1 & 1 & 1 \\
\hline $\mathbf{2}$ & 2 & 1 & 1 \\
\hline $\mathbf{3}$ & 3 & 1 & 1 \\
\hline $\mathbf{4}$ & 1 & 2 & 1 \\
\hline $\mathbf{5}$ & 2 & 2 & 1 \\
\hline $\mathbf{6}$ & 3 & 2 & 1 \\
\hline $\mathbf{7}$ & 1 & 3 & 1 \\
\hline $\mathbf{8}$ & 2 & 3 & 1 \\
\hline $\mathbf{9}$ & 3 & 3 & 1 \\
\hline $\mathbf{1 0}$ & 1 & 1 & 2 \\
\hline--- & --- & --- & --- \\
\hline $\mathbf{2 7}$ & 3 & 3 & 3 \\
\hline
\end{tabular}

\section{DoE Theory}

DoE is a collection of statistical methods that can be used to solve a design problem in many industries. Multiple input parameters, or factors, are varied between discrete levels and the effects on one or more output parameters, or Measures of Effectiveness (MoEs), are observed. ${ }^{3}$ Conducting a DoE study often involves defining and running a complete or full factorial experiment, which examines every permutation of factors and levels. ${ }^{4}$ The number of cases that must be tested in a full factorial experiment is determined by the number of factors and levels. For example, if 9 factors are varied at 3 levels, then running a full factorial study requires $3^{9}$ or 19,683 cases. Table 1 displays an example full factorial matrix for a study with 3 levels and 3 factors, for a total of $3^{3}$ or 27 cases.

By conducting an experiment using a test matrix like the one shown in Table 1, the effects on the MoEs from each combination of factors will be observed. Once all the experiments have been run, the results can be examined using Analysis of Variance (ANOVA), a statistical method to determine significant interactions between factors and combinations of factors. ANOVA calculates $p$-values, indicating which interactions are significant, as well as mean square and $F$-values that show the relative degree of significance for each interaction. In addition, plots produced by an ANOVA computer program can be used to graphically represent complex interactions.

\section{Implementation of DoE with CPAS Simulation Tools}

DoE is applied to CPAS by conducting a full factorial experiment using parachute simulations. The MoEs chosen for the CPAS DoE study are the parachute flight performance parameters: inflation loads and terminal ROD. For the preliminary DoE studies, two types of variables were used as factors: parachute inflation factors and physical factors. Each of these factors, listed in Table 2, is defined either in Knacke's parachute design manual ${ }^{5}$ or in the CPAS model memo. ${ }^{6}$

Table 2. DoE factors used in preliminary CPAS studies

\begin{tabular}{|l|l|}
\hline Factor & Definition \\
\hline$n$ & Canopy fill constant \\
\hline expopen & Opening profile shape exponent \\
\hline$C_{D}$ & Drag coefficient (of full-open parachute) \\
\hline$C_{k}$ & Over-inflation factor \\
\hline$t_{k}$ & Time to ramp down after stage over-inflation \\
\hline$\varepsilon$ & Reefing ratio for inflation stage \\
\hline $\bar{q}$ & Dynamic pressure \\
\hline Weight & Total vehicle weight \\
\hline
\end{tabular}

\section{A. Relating Parachute Inflation Factors to the Drag Area Curve}

The first five factors are the parachute inflation factors. The values and dispersions of these factors are derived from flight test data and are published in the CPAS model memo. Each of these factors directly affects the drag area $\left(C_{D} S\right)$ curve, shown in Fig. 1. Parachute loads are roughly equal to drag area multiplied by dynamic pressure; therefore, changes in drag area directly affect loads.

The $C_{D} S$ curve for each parachute stage is made up of four components: a) an exponential growth segment, b) a linear over-inflation segment, c) a ramp down segment, and d) a constant segment. 
The exponential growth segment (a) of the $C_{D} S$ curve begins at initial time, $t_{i}$ and ends after the elapsed stage fill time, $t_{f}$. Fill time is defined by Eq. (1), where $D_{o}$ is the parachute diameter, $V_{i}$ is the initial airspeed, $\varepsilon_{i}$ is the initial reefing ratio, $\varepsilon_{i+l}$ is the final reefing ratio, and $n$ is the canopy fill constant.

$$
\mathrm{t}_{\mathrm{f}}=\mathrm{n} \cdot \mathrm{D}_{\mathrm{o}} \cdot \frac{\sqrt{\varepsilon_{\mathrm{i}+1}-\varepsilon_{\mathrm{i}}}}{\mathrm{V}_{\mathrm{i}}}
$$

Drag area growth for segment (a) as a function of time is given by Eq (2), where $\left(C_{D} S\right)_{a}$ is the initial drag area, $\left(C_{D} S\right)_{b}$ is the final drag area, $t$ is the simulation time, and expopen is the opening profile shape exponent.

$$
\left(C_{D} S\right)(t)=\left(C_{D} S\right)_{a}+\left(\left(C_{D} S\right)_{b}-\left(C_{D} S\right)_{a}\right) \cdot\left(\frac{\left(t-t_{i}\right)}{t_{f}}\right)^{\text {expopen }}
$$

At the end of segment (a), when the drag area first reaches $\left(C_{D} S\right)_{\mathrm{b}}$, the $C_{D} S$ curve becomes linear for the duration of segment (b) until $\left(C_{D} S\right)_{\text {peak }}$ is reached. The infinite mass over-inflation factor, $C_{k}$, defined in Eq. (3) determines the value of $\left(C_{D} S\right)_{\text {peak }}$.

$$
\mathrm{C}_{\mathrm{k}}=\frac{\left(\mathrm{C}_{\mathrm{D}} \mathrm{S}\right)_{\text {peak }}}{\left(\mathrm{C}_{\mathrm{D}} \mathrm{S}\right)_{\mathrm{b}}}
$$

As soon as the peak value is reached, segment (c) begins, and the drag area decreases according to the ramp down function given by Eq. (4), where $t_{f p}$ is the elapsed time to peak drag area and $t_{k}$ is the time to ramp down after stage over-inflation. Eq. (4) is valid until a time $t_{k}$ has elapsed, at which point segment (c) ends and the $C_{D} S$ curve becomes constant for the duration of segment (d) until the next stage begins.

$$
\left(\mathrm{C}_{\mathrm{D}} \mathrm{S}\right)(\mathrm{t})=\left(\mathrm{C}_{\mathrm{D}} \mathrm{S}\right)_{\text {peak }} \cdot\left(\mathrm{C}_{\mathrm{k}}\right)^{\left(\mathrm{t}_{\mathrm{fp}}+\mathrm{t}_{\mathrm{i}}-\mathrm{t}\right) / \mathrm{t}_{\mathrm{k}}}
$$

In CPAS simulations, Drogues and Pilots are modeled with infinite mass inflation (including over-inflation) and Mains are modeled with finite mass inflation. For finite mass inflation, $C_{k}$ is equal to 1 and there is no over-inflation. As a result, values of $C_{k}$ and $t_{k}$ are not reported for CPAS Mains.

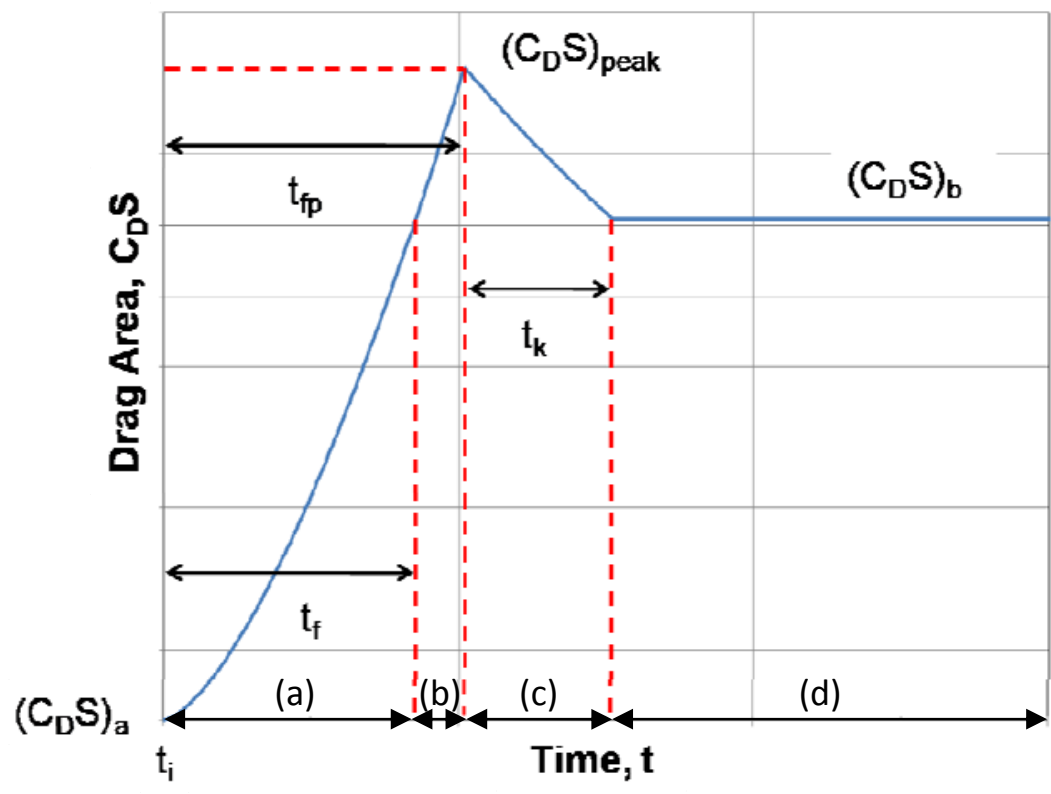

Figure 1. Drag area curve for a single parachute disreefing stage ${ }^{6}$

$t_{i}=$ initial time; $t_{f}=$ stage fill time; $t_{f p}=$ stage time to peak drag area;

$t_{k}=$ time to ramp down after stage over-inflation; $\left(C_{D} S\right)_{a}=$ initial drag area;

$\left(C_{D} S\right)_{\text {peak }}=$ peak drag area; $\left(C_{D} S\right)_{b}=$ final drag area

American Institute of Aeronautics and Astronautics 


\section{B. Conducting CPAS DoE Studies in MCDS}

For the initial full factorial studies described in this paper, each factor was varied to either two or three levels. Each level corresponds to the minimum, maximum, and nominal dispersion values from the model memo. It is possible to conduct DoE studies with more levels, providing a higher resolution of results, but the number of runs increases rapidly and is limited by available memory and processing power.

DoE is implemented in MATLAB by a modified version of the CPAS Monte Carlo Decelerator Simulation (MCDS), ${ }^{7}$ a tool used to run and display output from multiple parachute simulation runs. First, MCDS sets up all the necessary parameters and options to run the chosen parachute simulation (usually DSS or DSSA). In the process, it creates a MATLAB data structure containing the values of each factor at each level, as well as default values for other input parameters. Next, a full factorial matrix, similar to Table 1, is produced using the MATLAB Statistics Toolbox. MCDS then runs through each row of the matrix, choosing factor values for each case according to the content of that row. Once all the cases have been run, MCDS opens an interactive plotting utility that displays the output data.

\section{Interpreting DoE Results}

After a DoE study has been run, the results are interpreted in several ways. Any cases exhibiting significant or interesting effects are isolated to be examined more closely. For example, if DoE is being used to verify the requirements on parachute flight performance parameters, then results outside of the requirements need to be investigated and explained. This often involves additional DoE studies focusing on a tighter dispersion of factors around the suspect cases. These studies may reveal potential data gaps that can be filled through additional hardware or flight tests.

In addition, ANOVA can also be used to identify factors and combinations that cause large variations in MoE values, compare degrees of significance, and plot complex interaction effects. ANOVA provides results that can help determine if parachute parameters currently modeled independently are actually interrelated. Quantifying the effects of input parameters on parachute performance through DoE provides statistical grounds to validate parachute models and justifies the use of those models to verify requirements.

\section{Preliminary DoE Studies in DSSA}

The preliminary DoE studies discussed in this section were built from the DSSA case file for a CPAS Cluster Development Test (CDT-2-3). The factors used in this DoE study are unique for each parachute stage, but were varied only for the first stage of the Drogue parachutes. Factors for all subsequent Drogue and Main parachute stages were held constant at their nominal values.

\section{A. $2^{8}$ study (256 cases)}

The first study was conducted to establish architecture for DoE and investigate the usefulness of DoE results. This study consisted of 2 levels and 8 factors for a total of $2^{8}$ or 256 cases. MCDS took about 35 minutes to execute and process 256 DSSA runs. The 8 factors included 5 parachute inflation parameters $\left(n\right.$, expopen, $C_{D}, C_{k}$, and $\left.t_{k}\right)$ and 3 physical parameters $(\varepsilon, \bar{q}$, and Weight). The physical parameters were held constant in this study because they do not have well-defined dispersions, but they can easily be varied in the future. They were included to provide a more complete picture of all the factors affecting parachute performance. Because the physical parameters are held constant, this particular study only shows the effects of the 5 parachute inflation parameters. Therefore, only the first

$2^{5}$ or 32 cases are unique; the rest of the 256 cases are duplicates and are not included in the results.

Several observations were made from the results of this study. First, CPAS Analysis Engineers had intuited that ROD is driven by $C_{D}$, which this study confirmed. The statistics plot shown in Fig. 2 indicates that ROD varies by almost exactly $\pm \sigma$. The MDCS statistics plotting utility allows the user to select a specific point and determine the value of each factor for the case that point represents. Such an investigation reveals that all the cases clustered around $+\sigma$ have a high $C_{D}$ and all the cases clustered around $-\sigma$ have a low $C_{D}$. This indicates that the other inflation parameters likely do not have much effect on ROD. ROD was examined in the follow-up $3^{5}$ study as well, but the results were almost identical. It was decided that DoE studies should focus on parachute inflation loads for the time being, and a more detailed study of ROD could be conducted at a later time. It should be noted that the $C_{D}$ values reported in the model memo are best fits from test reconstructions of ROD and do not necessarily match the actual steady-state $C_{D}$ of the parachutes, because ROD is driven by cluster dynamics. ${ }^{8}$ 


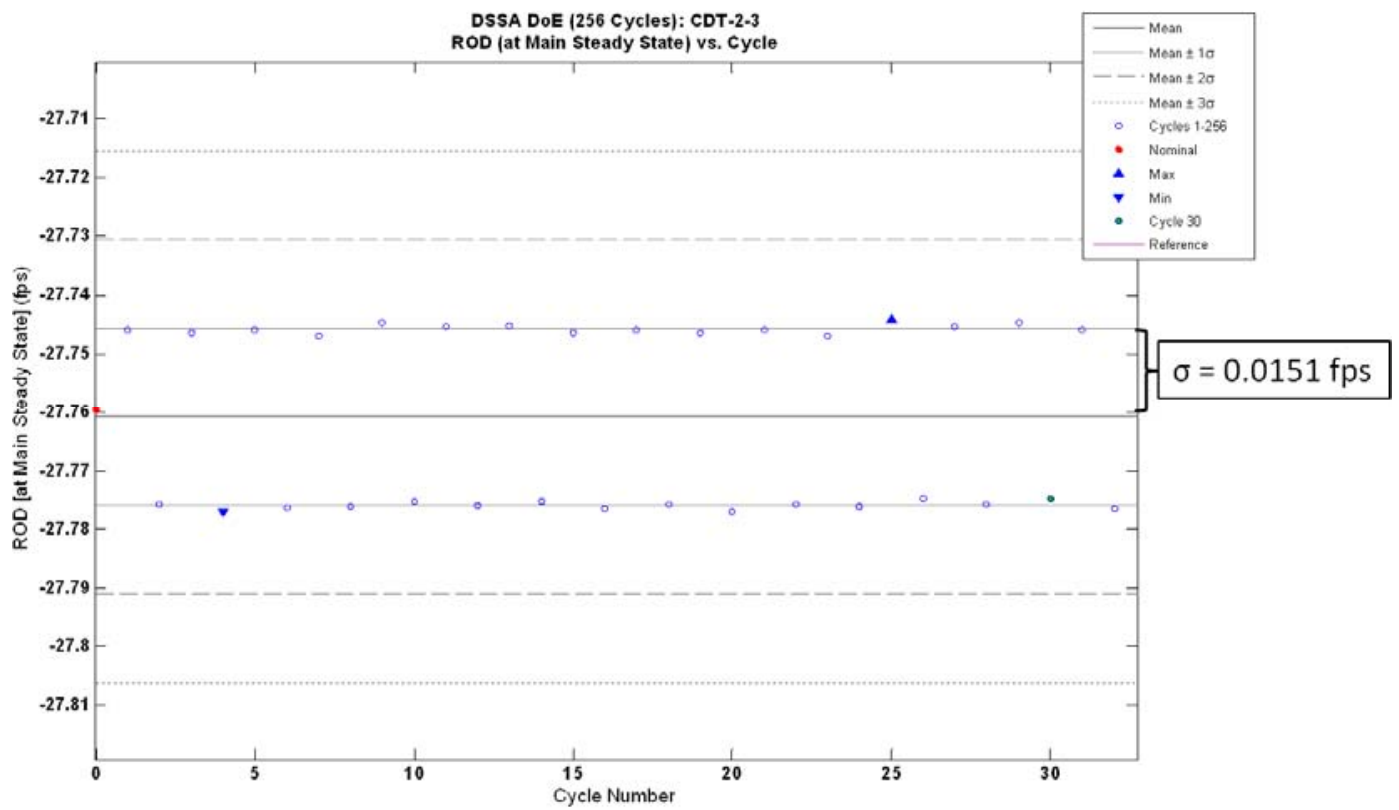

Figure 2. Statistics Plot for Terminal ROD from $2^{8}$ study, zoomed in to show the 32 unique cases

The effects on peak load for the first stage of the Drogue parachutes were also examined. The variation in peak loads is shown in Fig. 3 on a plot of Drogue riser load versus time. The highest loads $(\approx+2 \sigma)$ occurred when $C_{D}$, expopen, and $C_{k}$ were at their maximum values and $n$ was at its minimum value. This indicates that significant interaction in loads probably exists between three inflation parameters: $n$, expopen, and $C_{k}$. It also revealed that some factors do not significantly affect peak loads, but a more thorough analysis with ANOVA was required to obtain higher fidelity results.

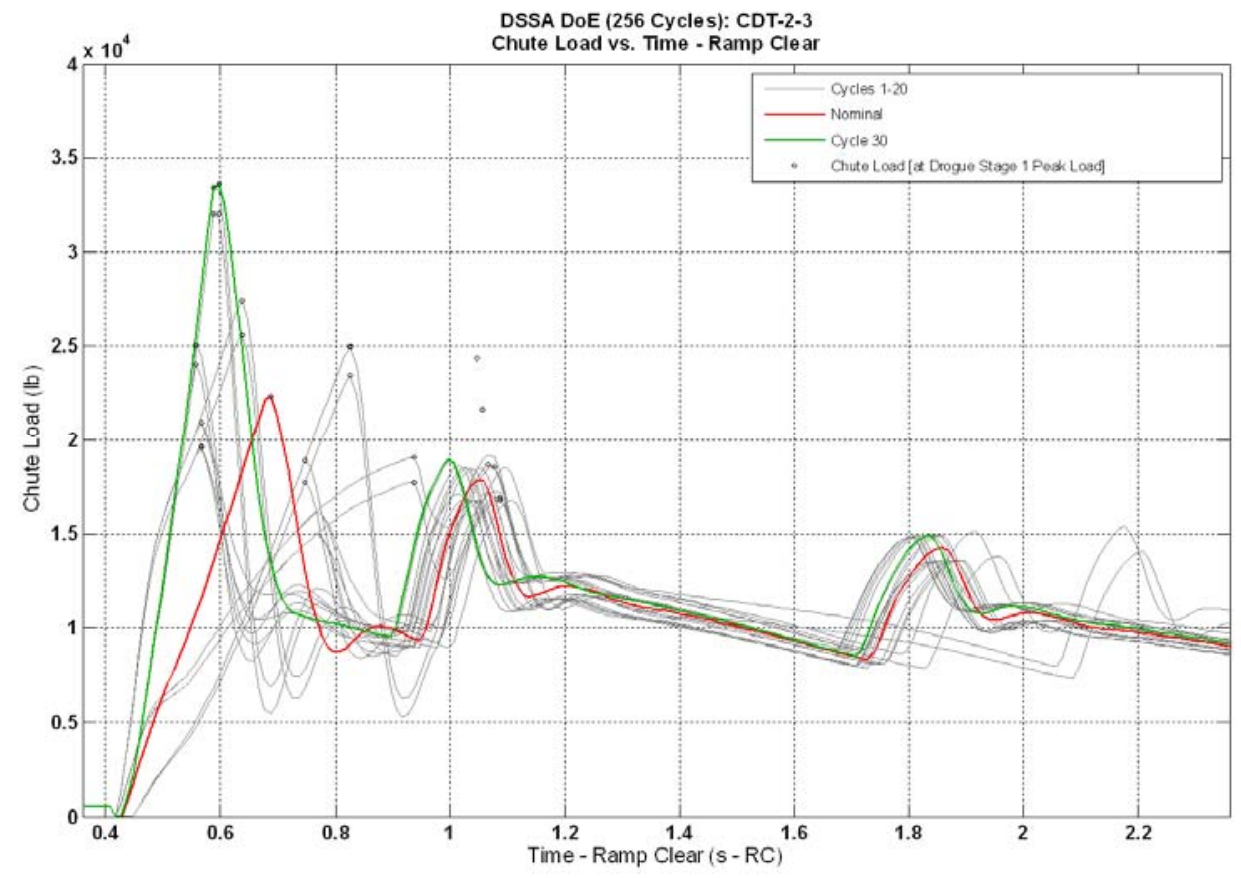

Figure 3. Load traces from $2^{8}$ study with peak loads for Drogue stage 1 indicated by dots. Due to memory constraints, only the first 20 load traces are plotted here, but all peak loads are shown.

American Institute of Aeronautics and Astronautics 


\section{B. $3^{5}$ study (243 cases)}

A follow-up study was conducted using three levels (maximum, minimum, and nominal) to improve the fidelity of results. To keep processing time down, the physical parameters were removed, leaving only the 5 parachute inflation parameters as factors. With 3 levels and 5 factors, this study encompassed $3^{5}$ or 243 cases, and took about 30 minutes to execute and process in MCDS. As shown in Fig. 4, the peak load distribution was wider, and the peaks did not overlap as much as in the two level study. Also, the same factors influenced peak loads as in the $2^{8}$ study; the highest loads were at the same values, but they were farther from the mean for the $3^{5}$ study.

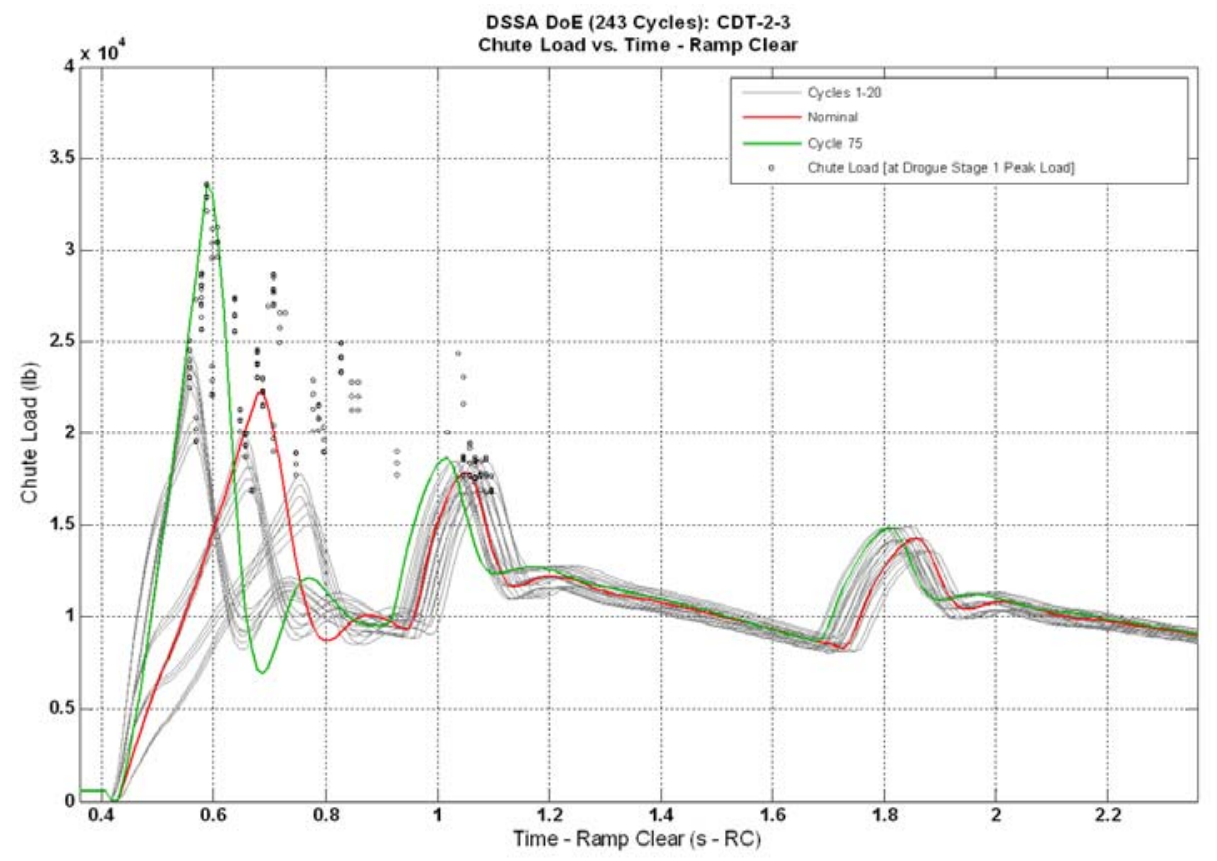

Figure 4. Load traces from $3^{5}$ study with peak loads for Drogue stage 1 indicated by dots. Due to memory constraints, only the first 20 load traces are plotted here, but all peak loads are shown.

Table 3. ANOVA results from $3^{5}$ study

\begin{tabular}{|c|c|c|c|c|c|}
\hline \multicolumn{6}{|c|}{ Analysis of Variance } \\
\hline Source & Suan Siq. & d. $f$. & Mean Sq. & F & Prob $>F$ \\
\hline sal & 90226931.4 & 2 & 45113465.2 & 420.39 & 0. \\
\hline$n$ & 1602961572 & 2 & 801480786 & 7468,68 & 0 \\
\hline expopen & 646971496 & 2 & 323485748 & 3014.44 & 0 \\
\hline $\mathrm{Ck}^{2}$ & 1380350966,3 & 2 & 690175483,2 & 6431,47 & 0 \\
\hline ek & --2251240.2 & $-\frac{2}{4}$ & $\begin{array}{r}1125620.1 \\
--74095: \frac{8}{8}\end{array}$ & $--\frac{10.49}{0.69}$ & $\frac{0.0001}{0.5-01}$ \\
\hline $\mathrm{Cd}^{\star}$ expopen & 759447.3 & 4 & 189861.8 & 1.77 & 0.1399 \\
\hline $\mathrm{Cd} * \mathrm{Cz}$ & 589214.1 & 4 & 147303.5 & 1.37 & 0.2479 \\
\hline $\mathrm{Cd}^{*} \mathrm{tk}$ & 35452.4 & 4 & 8863.1 & 0.08 & 0.9876 \\
\hline $\mathrm{n}^{*}$ expopen & 65481247.7 & 4 & 16370311.9 & 152.55 & 0 \\
\hline $\mathrm{n}^{*} \mathrm{Ch}$ & 66482900.2 & 4 & 16620725.1 & 154.88 & 0 \\
\hline$n * t h$ & 3091174.9 & 4 & 772793.7 & 7.2 & 0 \\
\hline exmonental: & $\operatorname{szn} 48280$ & 4 & 130120701 & 12125 & n. \\
\hline expopen*th & 2864367.1 & 4 & 716091.8 & 6.67 & 0.0001 \\
\hline 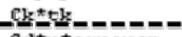 & 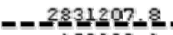 & -4 & --207801.9 & $-6.6-$ & 20.0001 \\
\hline $\mathrm{Cd}^{*} \mathrm{n}^{*}$ expopen & 159288,1 & 8 & 19911 & 0.19 & 0.99251 \\
\hline$C d^{*} n * C l$ & 105136 & 8 & 13142 & 0.12 & 0.9982 \\
\hline$C \mathrm{~d}^{*} \mathrm{n}^{*} \mathrm{th}$ & 41245,3 & 8 & $5155, ?$ & 0,05 & $0.9999 i$ \\
\hline 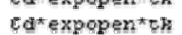 & 3910.6 & 8 & 4888.8 & 0.05 & 1 \\
\hline $\mathrm{c}^{*} \mathrm{Ck}^{\star} \mathrm{t} \mathrm{k}$ & $50092-$ & 8 & $-6262-4$ & $0,06$. & $0.9299^{1}$ \\
\hline$n *$ expopen $* C k$ & $319,5994.9$ & 8 & 399499.4 & 3.22 & a. $000 ?$ \\
\hline $\mathrm{n}^{*}$ expopentok & 6297521.9 & a & 787196.5 & 7,34 & 0 \\
\hline $\mathrm{n} * \mathrm{Ck} * \mathrm{Ck}$ & 5483887.2 & 8 & 685485.9 & 6.39 & 0 \\
\hline expopen*Ck*tk & 5640867,8 & 8 & 705108,5 & 6.57 & 0 \\
\hline Exrox & 12126280.1 & 113 & 107312.2 & & \\
\hline Total & 3950321453,9 & 243 & & & \\
\hline
\end{tabular}

ANOVA was applied to this study to obtain more detailed results. The ANOVA results, shown in Table 3, highlight the factors and combinations that have a large effect on peak load variation. Low $p$-values (Prob $>$ F), below an arbitrary probability of $\alpha=0.05$, indicate that an interaction is statistically significant. Interactions with higher mean square and $F$-values are more significant, even if they have the same $p$-values.

The interactions boxed by dashed lines in Table 3 are statistically insignificant because they have $p$-values higher than 0.05 . These are all combinations involving $C_{D}$, indicating that there are no significant interactions between drag coefficient and any other factor. The factors and interactions boxed by solid lines in Table 3 are the most significant. They all have $p$ values of zero and very high mean square values. According to this table, the three most significant factors, both alone and in combination, are $n$, expopen, and $C_{k}$. The 
unboxed factors and combinations are only marginally significant. From these results, it can be concluded that loads are fundamentally a function of three parachute inflation parameters: $n$, expopen, and $C_{k}$. First order interactions between these three are also significant, but no two or three way interactions have as much of a contribution as the individual factors.

\section{C. $3^{3}$ study ( 27 cases)}

The next step involved isolating only the three most significant parameters. Again, 3 factors were used with 3 levels each, resulting in $3^{3}$ or 27 cases. The main goal of this study was to examine the significant interactions between parameters. An ANOVA analysis, shown in Table 4, revealed that all individual factors and first order interactions were statistically significant, with individual factors much more significant than the combinations. The most significant factor was $n$, followed by $C_{k}$ and expopen.

Main effects plots reveal the peak load trends for each of these factors. Fig. 5 shows that peak loads are inversely proportional to $n$ and directly proportional to expopen and $C_{k}$. The multi-vari plots, shown in Fig. 6, indicate that these trends generally hold even when considering complex interactions between the three factors. One interesting anomaly is denoted by the circled cluster of points in Fig. 6a. At this particular combination of two factors (high $n$ and low $C_{k}$ ), the peak load trend in the third factor, expopen is not completely consistent with all the other cases. This indicates that some combinations of two factors can affect peak load trends in the third factor and that one or more of the dispersed parameter values may need to be reevaluated. Though seemingly insignificant, this effect warrants closer examination, and the next study investigates it in more detail.

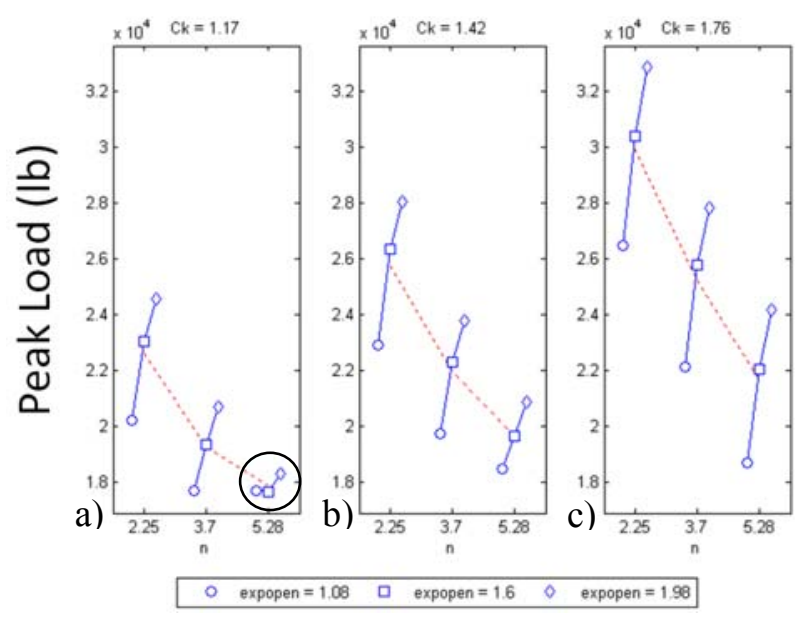

Figure 6. Multi-vari plots from $3^{3}$ study. Each plot has a constant $C_{k}$ with $n$ varied along dashed lines and expopen varied along solid lines.

Table 4. ANOVA results from $3^{3}$ study

\begin{tabular}{|c|c|c|c|c|c|}
\hline \multicolumn{6}{|c|}{ Analysis of Variance } \\
\hline Source & Sum Sq. & d. $f$. & Mean Sq. & $\mathrm{F}$ & Prob $>F$ \\
\hline $\mathrm{n}$ & $1.85883 e+008$ & 2 & 92941663.6 & 575.74 & 0 \\
\hline expopen & $7.78537 \mathrm{e}+007$ & 2 & 38926846.8 & 241.14 & 0 \\
\hline $\mathrm{Cl}$ & $1.45572 \mathrm{e}+008$ & 2 & 72785762.2 & 450.88 & 0 \\
\hline $\mathrm{n}^{*}$ expopen & $5.0804 e+006$ & 4 & 1270099.1 & 7.87 & 0.0071 \\
\hline $\mathrm{n} * \mathrm{Ck}$ & $9.88567 e+006$ & 4 & 2471417 & 15.31 & 0.0008 \\
\hline expopen $* \mathrm{Ck}$ & $8.14603 e+006$ & 4 & 2036508.2 & 12.62 & 0.0016 \\
\hline Error & 1. $29145 e+006$ & 8 & 161431.2 & & \\
\hline Total & $4.33712 e+008$ & 26 & & & \\
\hline
\end{tabular}
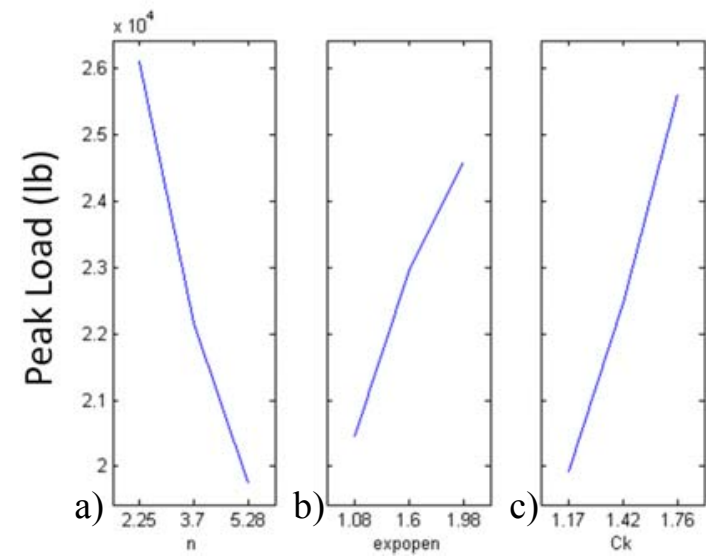

Figure 5. Main effects plot from $3^{3}$ study

\section{D. $5^{3}$ study (125 cases)}

For the final study, the dispersion range on each of the three most significant factors was doubled to see if peak load trends hold or break down for a wider dataset outside the range of flight test experience. The same 3 factors were used as in the previous study, but with 5 levels instead of three for a total of $5^{3}$ or 125 cases. The middle three levels were the same as the original three, reflecting the model memo dispersions for each factor, but the outer two levels encompassed an extension of the dispersion ranges. To calculate the "double dispersions," the difference between each model memo nominal and dispersed value was doubled. For example, the nominal $n$ value was 3.7 and the model memo dispersion minimum was 2.25 , so the double dispersion minimum is 0.8 . Because the model memo dispersions are not necessarily equally distributed about the nominal value, neither are the doubly dispersed values. In other words, the minimum dispersed value might be further from the nominal than the maximum dispersed value, or vice 
versa. The first significant result is that outside of the model memo dispersion range, $C_{k}$ has a larger effect on peak loads than $n$. In addition, as shown in Fig. 7, peak load trends still hold for individual factors.
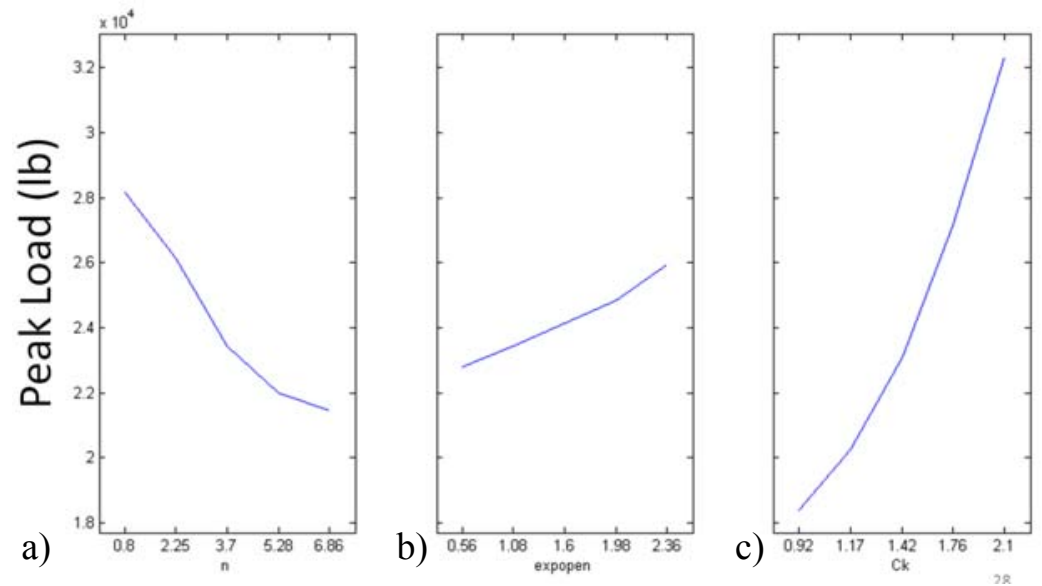

Figure 7. Main effects plot from $5^{3}$ study

However, many peak load trends do not hold for complex interactions outside of the model memo dispersion range. These trend breakdowns can be seen dramatically in Fig. 8 as tight clusters of points and large zigzags. The tight clusters of points in Fig. $8 \mathrm{a}$ and $8 \mathrm{~b}$ indicate that there is little variation in peak loads as one factor changes value. In contrast, the large zigzags in Fig. 8c, 8d, and 8e indicate large discrepancies in peak load values as one factor changes. These results actually help to validate the simulation model because they show that the effect of complex interactions outside the model memo dispersion range do not follow predictable trends. Part of the reason for these results is that some factor values outside the dispersion range are not realistic. For example, any values of $C_{k}$ less than 1, although included in this study as shown in Fig. 8a, are not physically possible. The breakdown of trends outside the standard dispersion range suggests that the dispersion limits have been set at appropriate values.
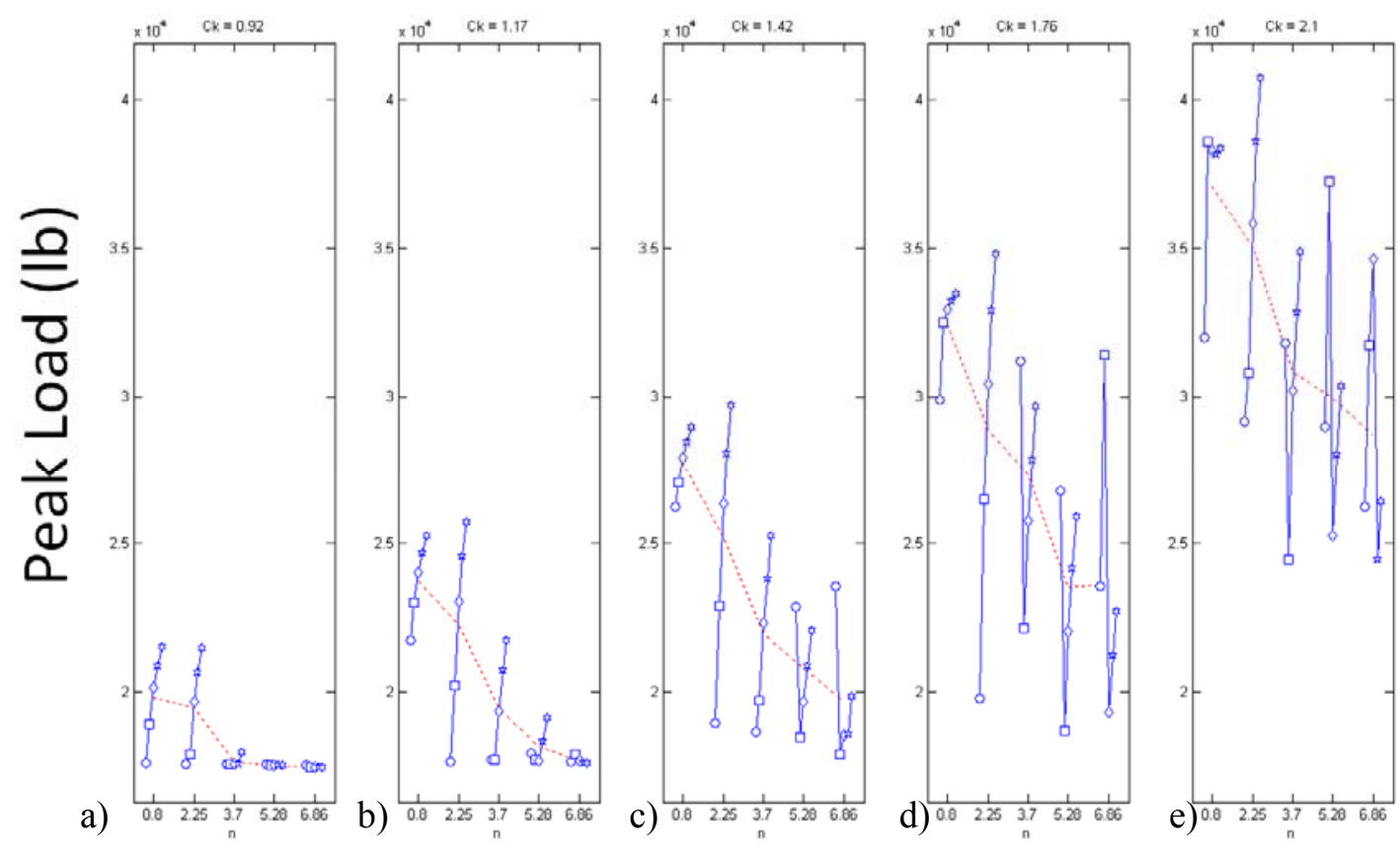

expopen $=0.56$ axpopen $=1.00 \quad \bullet \quad$ expopen $=1.6 \quad *$ expopen $=1.90 \%$ expopen $=2.36$

Figure 8. Multi-vari plots from $5^{3}$ study. Each plot has a constant $C_{k}$ with $n$ varied along dashed lines and expopen varied along solid lines.

American Institute of Aeronautics and Astronautics 


\section{Conclusion}

The results of the preliminary DoE studies presented in this paper raise some interesting questions about the way parachute inflation is currently modeled. First, the results indicate that the value of $C_{k}$ may not be completely independent, but rather a complex function of several factors. If this is true, it may be not be advantageous to continue dispersing values for $C_{k}$ separately from the other factors that drive it. In addition, the breakdown in peak load trends for certain combinations of factors indicates that some combinations of values within the model memo dispersion range may not be physically possible. One possible remedy is to bound the drag area curve in addition to dispersing each parameter individually. If any combination of parameters results in a drag area curve that does not correspond to a possible physical parachute inflation, that case and its results would be ignored.

There is significant forward work still to be done on the CPAS DoE study. First, the preliminary DSSA studies described in the previous section need to be rerun in DSS, because it is the primary simulation tool used to verify requirements. Second, the studies described in this paper only varied parameters for the first stage of the Drogue parachutes and need to be extended to subsequent Drogue and Main stages. In addition, physical parameters such as reefing ratio, weight, and initial $\bar{q}$ should be dispersed. Finally, CPAS requirements must be verified using benchmark cases representative of integrated CEV flight reentry and abort trajectories. These benchmark cases need to be developed and studied so CPAS can see how well the requirements are met.

DoE helps perform two main functions for the CPAS project: validation of simulation models and verification of parachute flight performance requirements. Results from DoE studies provide statistical measures of the effects of input parameters on parachute performance. DoE also offers a unique perspective from Monte Carlo simulations because it accounts for interactions between input parameters rather than varying each parameter randomly. If CEV trajectories and parachute performance can be accurately modeled, DoE has the potential to aid in validating model memo parameter dispersions and verifying that requirements will not be violated.

\section{References}

\footnotetext{
1“"Project Technical Requirements Specification for the Crew Exploration Vehicle (CEV) Parachute Assembly System (CPAS),” JSC-63497 Rev B, May 2010.

${ }^{2}$ Morris, A., Olson, L., "Verification and Validation Plan for Flight Performance Requirements on the CEV Parachute Assembly System," $21^{\text {th }}$ AIAA Aerodynamic Decelerator Systems Technology Conference and Seminar, Dublin, Ireland, May 2011 (submitted for publication).

${ }^{3}$ Willcox, K., "Multidisciplinary System Design Optimization (MSDO), Design Space Exploration Lecture 5," Massachusetts Institute of Technology, February 2004.

${ }^{4}$ Mendenhall, W., Introduction to Linear Models and The Design and Analysis of Experiments, Wadsworth Publishing Company, Inc, Belmont, California, 1968.

${ }^{5}$ Knacke, T.W., "Parachute Recovery Systems Design Manual," U.S. Navy Report NWC TP-6575, Para Publishing Co., Santa Barbara, CA, 1992.

${ }^{6}$ K. Bledsoe, U. Fraire, J. Moore, A. Morris, L. Olson, E. Ray, "Crew Exploration Vehicle (CEV) Parachute Assembly System (CPAS) Engineering Development Unit Operating Modeling Parameters Version 7a,” January 2011, ESCG-8400-CPAS10-MEMO-0070, Jacobs Technology Engineering and Science Contract Group.

${ }^{7}$ Moore, J., "Development of Monte Carlo Capability for Orion Parachute Simulations," $21^{\text {th }}$ AIAA Aerodynamic Decelerator Systems Technology Conference and Seminar, Dublin, Ireland, May 2011 (submitted for publication).

${ }^{8}$ Ray, E., "Measurement of CPAS Main Parachute Rate of Descent," $21^{\text {th }}$ AIAA Aerodynamic Decelerator Systems Technology Conference and Seminar, Dublin, Ireland, May 2011 (submitted for publication).
} 